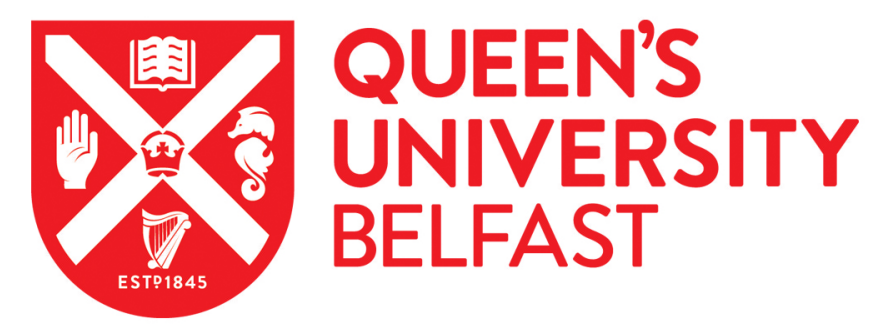

\title{
Evaluating the use of leaned stator vanes to produce a non-uniform flow distribution across the inlet span of a mixed flow turbine rotor
}

Morrison, R., Spence, S., Kim, S., Leonard, T., \& Starke, A. (2019). Evaluating the use of leaned stator vanes to produce a non-uniform flow distribution across the inlet span of a mixed flow turbine rotor. In Proceedings of ASME Turbo Expo 2019: Turbine Technical Conference and Exposition (pp. 1). [GT2019-90398] The American Society of Mechanical Engineers (ASME). https://doi.org/10.1115/GT2019-90398

Published in:

Proceedings of ASME Turbo Expo 2019: Turbine Technical Conference and Exposition

Document Version:

Peer reviewed version

Queen's University Belfast - Research Portal:

Link to publication record in Queen's University Belfast Research Portal

Publisher rights

(c) 2019 ASME.

This work is made available online in accordance with the publisher's policies. Please refer to any applicable terms of use of the publisher.

\section{General rights}

Copyright for the publications made accessible via the Queen's University Belfast Research Portal is retained by the author(s) and / or other copyright owners and it is a condition of accessing these publications that users recognise and abide by the legal requirements associated with these rights.

Take down policy

The Research Portal is Queen's institutional repository that provides access to Queen's research output. Every effort has been made to ensure that content in the Research Portal does not infringe any person's rights, or applicable UK laws. If you discover content in the Research Portal that you believe breaches copyright or violates any law, please contact openaccess@qub.ac.uk. 


\section{GT2019-90398}

\section{EVALUATING THE USE OF LEANED STATOR VANES TO PRODUCE A NON-UNIFORM FLOW DISTRIBUTION ACROSS THE INLET SPAN OF A MIXED FLOW TURBINE ROTOR}

\author{
Richard Morrison, Stephen Spence, Sung In Kim \\ School of Mechanical and Aerospace Engineering \\ Queen's University Belfast, Belfast, UK
}

\author{
Thomas Leonard, Andre Starke \\ $\mathrm{IHI}$ Charging Systems International $\mathrm{GmbH}$ \\ Heidelberg, Germany
}

\begin{abstract}
Current trends in the automotive industry have placed an increased emphasis on downsized turbocharged engines for passenger vehicles. The turbocharger is increasingly relied upon to improve power output across a wide range of engine operating conditions, placing a greater emphasis on turbocharger offdesign performance. An off-design condition of significant importance is performance at low turbine velocity ratios, since it is relevant to engine transient response and also to efficient energy extraction from pressure pulses in the unsteady exhaust flow. An increased focus has been placed on equipping turbochargers with mixed flow turbine rotors instead of conventional radial flow turbine rotors to improve off-design performance and to reduce rotor inertia.

A recognized feature of a mixed flow turbine is the spanwise variation of flow conditions across the blade leading edge. This is a consequence of the reduction in leading edge radius from shroud to hub, coupled with the increasing tangential velocity of the flow due to conserved angular momentum as the radius decreases. The result is increasingly positive incidence towards the hub side of the leading edge. The resulting region of highly positive incidence at the hub produces separation from the suction surface and generates significant loss within the rotor passage.
\end{abstract}

The aim of this study was to determine if the losses in a MFT could be reduced by the use of leaned stator vanes, which deliberately created a significant spanwise variation of flow angle between hub and shroud at rotor inlet, to reduce the positive incidence at the hub. The turbine performance with a series of leaned vanes was compared against that of a straight vane using a validated CFD model. It was found that increasing vane lean improved turbine performance at all operating points considered. An increase of 3.2 percentage points in stage totalto-static efficiency was achieved at a key off-design operating point.

Experimental testing of a set of leaned vanes and the baseline vanes confirmed the advantage of the leaned vanes at all operating points, with an increase in measured efficiency of 2.6 percentage points at the key off-design condition. Unsteady
CFD models confirmed the same level of improvement at this operating point.

The CFD and experimental results confirmed that the losses in a MFT can be reduced by the use of leaned stator vanes to shape the flow at rotor inlet.

\section{INTRODUCTION}

In the automotive industry turbocharged downsized engines are increasingly used to meet exhaust emission standards and improve fuel economy. This has placed an increased emphasis on turbocharger off-design performance to ensure that adequate inlet boost pressure is produced across the full engine operating range.

The turbine efficiency characteristic is commonly correlated against the ratio of turbine blade tip speed to the flow isentropic spouting velocity, known as the velocity ratio $(U / C)$. Conventional radial flow turbines (RFTs) have an inlet blade angle of zero and are constrained to deliver peak efficiency at the relatively high $U / C$ of 0.7 [1]. For operating conditions below this ratio, turbine efficiency can be significantly compromised. This is a drawback for automotive applications as low $U / C$ operation can occur during important driving events. RFT performance is typically compromised at low U/C operation due to excessively positive incidence at the blade leading edge, which results in flow separation on the blade suction surface. A RFT will achieve peak efficiency with a moderate level of negative incidence, typically between $-20^{\circ}$ and $-30^{\circ}$ [1]. In addition to producing leading edge separation, the effects of positive incidence can significantly impact the flow field through the rotor passage [2].

Several methods have been demonstrated to potentially counteract the effects of positive incidence. One method that achieved positive results was using a RFT with a non-zero inlet blade angle [3]. The drawback of this approach was that the structural integrity of the blades was compromised by the bending stresses that resulted from the non-zero inlet blade angle. An alternative method to reduce positive incidence and potentially improve performance at low $U / C$ is to replace the RFT with a mixed flow turbine (MFT) [4]. The combination of 
radial and axial flow components at rotor inlet means that a MFT is capable of achieving a non-zero inlet blade angle without compromising the structural integrity of the rotor. Additionally, a MFT can also achieve lower rotational inertia and better turbocharger response compared to an equivalent RFT [5]. These factors make MFT rotors advantageous for improving turbocharger response to transient engine events.

A MFT differs from a RFT due to the angle of the flow in the meridional plane at rotor inlet relative to the rotational axis of the turbine, referred to as the flow cone angle $(\lambda)$, illustrated in Figure 1. For a RFT the flow is purely radial $\left(\lambda=90^{\circ}\right)$ and the leading edge tip radius is typically constant. This results in relatively uniform flow conditions across the span of the leading edge. For a MFT the inlet flow cone angle is not equal to $90^{\circ}$, as the flow has both axial and radial components. The leading edge of a MFT is typically inclined against the axis of rotation, by an angle referred to as the blade cone angle ( $\Lambda)$, as shown in Figure 1 [6]. As the flow has an axial component, the blade camber angle $(\Phi)$, illustrated in Figure 1 [7], can act to produce a nonzero inlet blade angle, $\left(\beta_{b}\right)$ which can be calculated using Eq. (1) [8].

For a MFT, increasing the flow cone angle or the blade camber angle will result in a larger blade inlet angle and therefore reduce positive incidence at off-design operation. The extent to which the flow cone angle can be increased is often limited by rotor overhang and packaging constraints on the turbine housing. Increasing the blade camber angle increases the flow turning in the passage, this can result in entropy generation downstream of the rotor leading edge on the suction surface [7].

As the leading edge tip radius is not fixed for a MFT, it experiences a spanwise variation of flow conditions, which is not typically experienced by a RFT. The most significant variation is the increase in incidence angle towards the hub. This is due to the reduction in blade tip speed with the smaller leading edge tip radius and larger flow angle which results from the increased tangential flow velocity due to the conservation of angular momentum. Leonard et al [6] examined the effects of changing MFT geometry and demonstrated that as the blade cone angle increased so did the variation of incidence angle across the leading edge, as illustrated in Figure 2. This was the result of the increased change in radius across the leading edge that occurred with larger blade cone angles. For a MFT with a blade cone angle of $60^{\circ}$ an increase in incidence angle across the span of $70^{\circ}$ was observed.

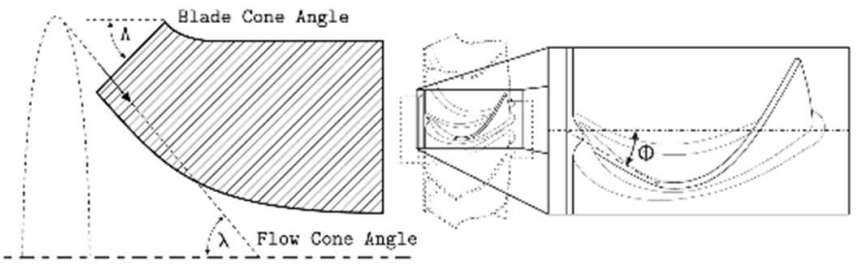

Figure 1 - MFT blade cone angle $(\Lambda)$, flow cone angle $(\lambda)$ (left [6]) and Blade camber angle $(\phi)$ (right [7])

$$
\tan \beta_{b}=\cos \lambda \tan \phi
$$

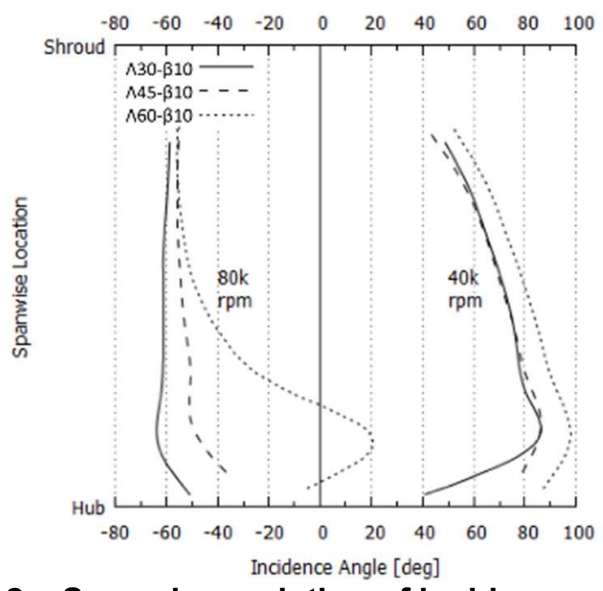

Figure 2 - Spanwise variation of incidence angle [6]

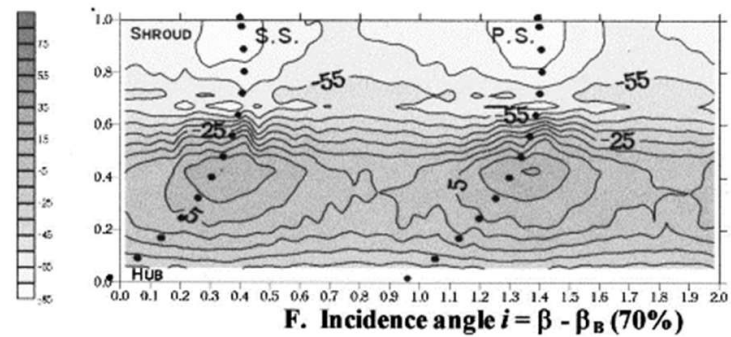

Figure 3 - Incidence angle contours at rotor inlet [9]

An increase in incidence angle towards the hub was also identified experimentally with Laser Doppler velocimetry measurements by Karamanis et al. [9]. At a high efficiency operating point the shroud side of the passage experienced a negative incidence angle, whereas towards the hub the incidence angle became increasingly positive, as shown in Figure 3 .

A study by Palfreyman and Martinez-Botas [10] comparing similar MFT and RFT rotors found that the MFT achieved a lower efficiency. The reduced efficiency of the MFT was attributed to positive incidence near the hub which resulted in flow separation on the blade suction surface, which was not observed in the RFT.

There exist few examples of MFTs with stator vanes. For the examples that do exist, the vanes are typically straight vanes derived from RFT systems. This results in a non-uniform vaneless space between the vane and rotor. This was identified by Rajoo and Martinez-Botas [11] who studied an alternative vane design which aimed to counteract this issue. The alternative vane design inclined the trailing edge against the hub surface by the same angle as the blade cone angle to produce a uniform vaneless space. The vane shroud profile was also elongated to improve uniformity between the hub and shroud surfaces of adjacent blades. The alternative blade design was experimentally tested at a number of different setting angles and the performance compared against that of both a nozzleless and a straight vane turbine. An efficiency improvement of up to 5 percentage points was observed compared to the nozzleless configuration. Similar efficiency values were obtained to that of the straight vane. 
However, the alternative vane design achieved a higher swallowing capacity, with an increase in mass flow parameter (MFP) of approximately $10 \%$. Although it was expected that the improved matching with the rotor leading edge would improve efficiency, it was proposed in the study that this advantage was offset by additional loss in the vane, primarily due to increased vane wetted area.

A numerical study of the impact of different spanwise distributions of flow angle on MFT performance was conducted by Morrison et al. [12]. This study imposed the desired flow distributions at the inlet to the rotor passage. It was determined that reducing the flow angle towards the hub side of the passage resulted in an efficiency improvement of $1 \%$ relative to a baseline case with a uniform distribution. A further study on the impact of inlet flow angle distributions on MFT rotor performance was conducted by Lee et al [13]. This study imposed five different spanwise flow velocity profiles at the inlet to a numerical model of a MFT rotor. For the flow profiles considered the most significant benefit was achieved for a profile with the same parabolic distribution produced by a baseline volute, but with the variation of flow angle across the span halved. This profile achieved an increase in total-to-static efficiency of $2.17 \%$.

Morrison et al. [12] and Lee et al. [13] have demonstrated that MFT performance can potentially be improved by altering the flow conditions at rotor inlet. However, the results of these studies were obtained by imposing the desired flow angle distributions and total pressure and temperature conditions directly upstream of the rotor leading edge. As the flow conditions were not produced by components upstream of the rotor, no validation of the different flow profile results could be provided. The rotors considered for the studies had shallow blade cone angles, reducing the change of radius across the leading edge and the resulting increase in incidence angle towards the hub. The impact of varying the spanwise distribution of inlet flow conditions could be more significant for rotors with large blade cone angles.

From the existing literature it has been demonstrated that MFT rotors experience significant loss due to separation from the suction surface near the hub and shaping of the flow profile upstream of the rotor inlet has the potential to reduce this loss. However, the limited studies on the effects of flow profiling lack rigorous experimental validation of the numerical results. It is also evident that research into stator vane design specific to MFTs is limited, however there is the potential for improved performance compared to conventional vane designs.

The aim of this study was to examine if losses in a MFT can be reduced by employing leaned stator vanes to produce a varied spanwise flow profile at the inlet to the rotor.

\section{METHODOLOGY OVERVIEW}

This study examined the impact of different spanwise distributions of inlet flow angle produced by a series of leaned stator vanes on the performance of a MFT rotor. A computational fluid dynamics (CFD) model was used to assess the impact of each vane configuration on turbine performance compared to a straight baseline vane. The performance of the vanes was initially considered at two operating points, representing design and off-design conditions for the turbine. The baseline vane and two leaned vanes were examined across three speed-lines to provide an understanding of the performance over a wider range of operating conditions.

The CFD approach consisted of steady-state single passage models with a stage mixing-plane interface between the vane and rotor. This approach was compared against a full $360^{\circ} \mathrm{CFD}$ model with a multiple reference frame interface and an unsteady transient simulation for the baseline vane and a selected leaned stator vane. The purpose of the comparison was to confirm that variations in performance of the single passage models were due to real physical phenomenon and not numerical error.

To provide validation of the CFD models and additional confidence in the results, the baseline vane and leaned stator vane were the subject of an experimental test programme. The experimental testing was conducted on the axis-symmetric cold flow turbine test facility at Queen's University Belfast (QUB). In addition to measuring global turbine performance, the experimental tests provided pressure measurements at key locations and flow field measurements at rotor exit.

\section{TURBINE GEOMETRY AND OPERATING CONDITIONS}

The MFT examined in this study was a custom design created as part of previous studies at QUB $[6,7]$. The MFT rotor was developed from a state-of-the-art automotive turbocharger RFT and scaled to an inlet tip diameter of $90 \mathrm{~mm}$ to allow for improved instrumentation during experimental testing. The turbine featured 9 blades with a nominally constant inlet blade angle of $20^{\circ}$. The turbine had a blade cone angle of $45^{\circ}$ and has previously demonstrated a significant increase in incidence angle towards the hub side of the leading edge [6]. Compared to the RFT it was derived from, the MFT had a lower peak efficiency and lower efficiency at high $U / C$. However, it did achieve a minor efficiency improvement at low $U / C$. The MFT had a 37\% lower rotational inertia compared to the baseline RFT [7]. In automotive applications a lower efficiency turbine can still provide an improvement in engine response to transient events if combined with a sufficient reduction in rotational inertia [14].

The primary aim of this study was to examine performance at off-design operation, however, it was important that the impact at the design point was also considered. Therefore, two operating points were considered, one high speed point close to the design condition $(U / C=0.63)$ and one low speed off-design point $(U / C=0.33)$. The parameters for the operating points were scaled from those of a production waste-gate turbocharger.

\section{EXPERIMENTAL TEST FACILITY}

Experimental validation of the numerical approach was conducted using the QUB cold flow turbine test facility. In this test facility the conventional turbine volute is replaced by an axis-symmetric torus to provide uniform flow around the circumference of the rotor inlet. This allowed for validation of the single-passage CFD models and removed the requirement for $360^{\circ}$ simulations to capture the effects of the volute tongue. The 
flow angle typically imparted by the volute was produced by a pre-swirl vane row located between the torus and stator vanes.

The test facility is capable of accommodating the scaled rotor size which allowed for improved instrumentation, including pressure taps at selected locations. A low turbine inlet temperature $(400-450 \mathrm{~K})$ and thorough insulation of the test rig reduced experimental inaccuracies due to heat transfer. Efficiency calculations were based on temperature and pressure measurements taken upstream of the pre-swirl vanes and at the outlet of a mixing section downstream of the turbine diffuser. A swirl flow meter with an accuracy of $0.5 \%$ of the measured value was used to determine the volume flow rate, which was used to calculate the mass flow rate. A number of different loading compressors were used to allow for a wide range of operating conditions to be examined. The hardware required for the experimental testing, including the rotor and stator vanes, was manufactured at QUB, selected hardware is pictured in Figure 4. Information on the experimental measurement uncertainty is provided in Table 1 and repeatability of efficiency measurements for this test rig is typically within $0.3 \%$. A five hole probe, mounted on a traversing mechanism, was positioned downstream of the rotor exit. This allowed for flow field measurements to be gathered across the span of the rotor outlet. Further details on the test facility are provided by Leonard et al. [15].
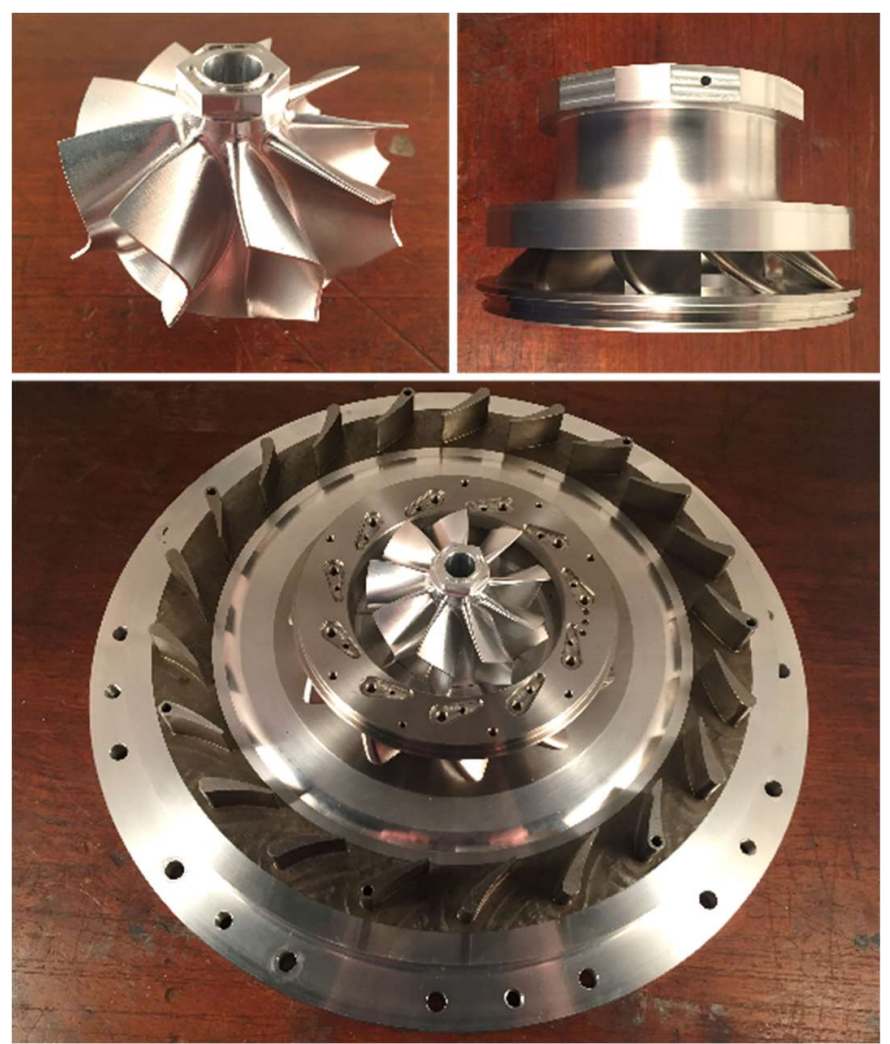

Figure 4 - Experimental hardware: rotor (top left), stator vane and shroud assembly (top right) and partial build up (bottom)

\section{Table 1 - Experimental measurement uncertainty}

\begin{tabular}{lc}
\hline \hline \multicolumn{1}{c}{ Parameter } & Uncertainty \\
\hline Turbine efficiency $(\mathrm{PR}=1.9)$ & $\pm 0.20 \% \mathrm{pts}$ \\
Turbine efficiency $(\mathrm{PR}=3.1)$ & $\pm 0.12 \% \mathrm{pts}$ \\
Mass flow parameter & $\pm 0.56 \%$ \\
\hline \hline
\end{tabular}

\section{NUMERICAL MODEL}

A numerical analysis was conducted using a 3-dimensional multi-domain CFD model produced in ANSYS-CFX. The model consisted of five separate domains: pre-swirl vane, stator vane, turbine rotor, backdisk cavity and exhaust diffuser.

The purpose of the pre-swirl vane row was to produce a flow angle similar to that of a turbine volute. Although it would have been less computationally demanding to numerically impose a flow angle at the inlet to the stator vane row for this purpose, the pre-swirl vanes were included to allow for direct validation with the experimental results gathered on the QUB test rig. The exhaust diffuser was also included to ensure the numerical model closely match the experimental facility.

The inlet to the pre-swirl vane domain was located at a radius 3.5 times that of the rotor inlet, this prevented the inlet boundary conditions of total pressure and total temperature from constraining the solution. It also provided sufficient space for the pre-swirl vane tailing edge wake to mix out, improving the circumferential uniformity of the flow field. The pre-swirl vanes were followed by a row of stator vanes, which produced the spanwise variation of flow angle required for the study. Information on the design of the stator vanes is provided in the 'Stator vane design' section of this report. A mixing-plane interface was used to connect the stator vane and rotor domains to account for the frame change. An overview of the computational model is provided in Figure 5.

As this study examined the effects of varying the flow conditions close to the hub side of the rotor leading edge, it was necessary to include the backdisk cavity of the rotor in the numerical model. This would ensure that any change to the cavity flow, and subsequent impact on the flow in the rotor passage, was accurately captured. The cavity geometry was scaled from the typical clearances of a production turbine. The cavity inlet was attached to the rotor hub surface and aligned with the blade leading edge. To allow the effects of the cavity to be accurately simulated in the model, the turbine hub surface was split into two discrete surfaces along the upstream side of the cavity inlet. The upstream hub surface represented the stationary hub endwall in the vaneless space and was defined in the model as a counter-rotating wall. The downstream hub surface was defined as a multiple reference frame interface with the cavity inlet. The cavity was defined as a rotating domain and the surface on the heatshield side was specified as a counter-rotating wall, as illustrated in Figure 6.

The numerical analysis employed the shear stress transport (SST) turbulence model, as it has provided good agreement with experimental test results in previous studies at QUB $[15,16]$. The 
meshes used in the numerical analysis consisted only of structured hexahedral elements. The stator vane and rotor meshes were produced with ANSYS TurboGrid and the cavity mesh was produced with ANSYS ICEM-CFD. The pitchwise distribution of elements at the cavity inlet was matched to that of the turbine hub at the location of the interface. This was to ensure that suitable refinement was achieved around the blade leading edge to capture the complex flow features in this region. The maximum mesh $y+$ value achieved was below 11 , and for the majority of the surfaces the $y+$ value was resolved to below 3 . To maintain continuity with existing hardware on the QUB cold flow test rig, the geometry and meshes for the pre-swirl vanes and exhaust diffuser were carried over from a previous study at QUB which had already conducted a grid independence study and validation with experimental results [15]. The numerical model used in this study also closely matched that used by Leonard et al. [15] as this modelling approach demonstrated good agreement with experimental results. The simulations were considered to be converged when the root-mean-square (RMS) residuals were below 1e-5 and key parameters were deemed to have reached a steady-state value.

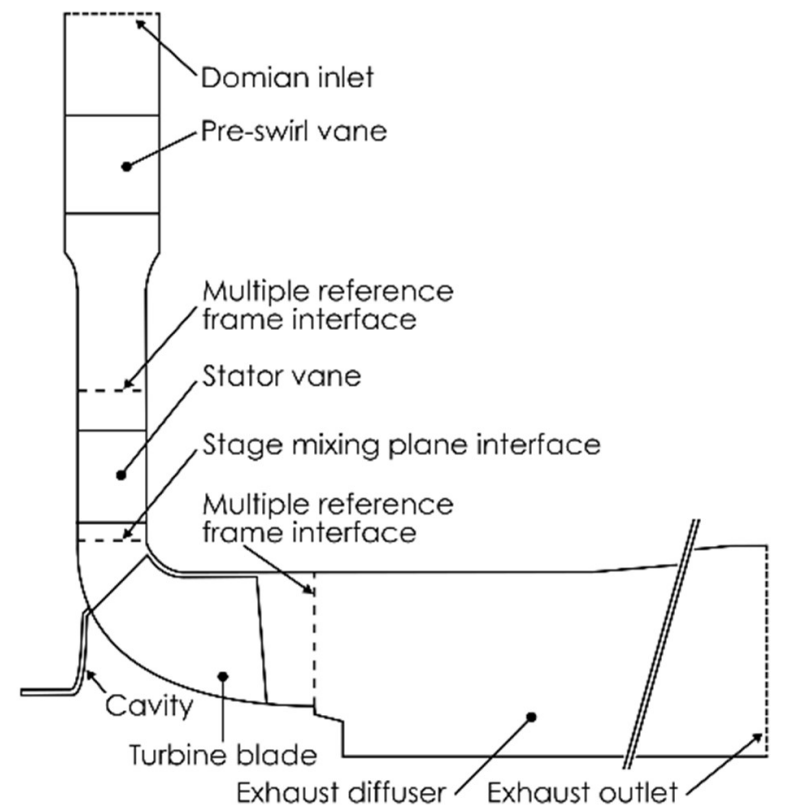

Figure 5 - Meridional view of computational model

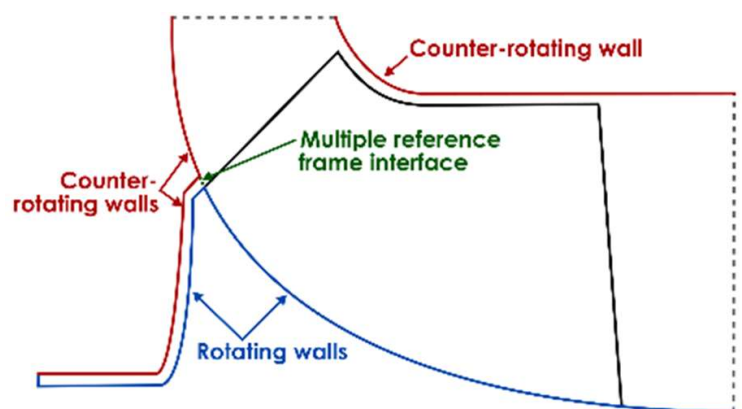

Figure 6 - Overview of rotor and cavity setup
To ensure that the results obtained were independent of the meshes used, a grid sensitivity study was conducted at the offdesign operating condition. The grid sensitivity study examined four different mesh densities for both the rotor and stator vanes and three for the backdisk cavity. The element counts for the meshes are provided in Table 2. Each of the rotor and stator meshes were considered together, producing a total of 16 different configurations. For the initial stage of the grid study the cavity mesh was not included. Results for selected configurations are provided in Figure 7 . The configurations which achieved the required global performance criteria were selected for a more detailed analysis of the passage flow field. This analysis determined that the 'fine' grade of mesh was the most suitable for the study. The cavity meshes were evaluated with the fine rotor and stator meshes and the medium density was selected as the most suitable.

Table 2 - Mesh element count per passage

\begin{tabular}{lccc}
\hline \hline & \multicolumn{3}{c}{ Passage Element Count (k) } \\
Mesh & Rotor (R) & Stator Vane (SV) & Cavity \\
\hline Coarse (C) & 366 & 287 & 72 \\
Medium (M) & 709 & 556 & 120 \\
Fine (F) & 1,333 & 1,025 & 213 \\
Extra Fine (EF) & 2,308 & 1,330 & N/A \\
\hline \hline
\end{tabular}

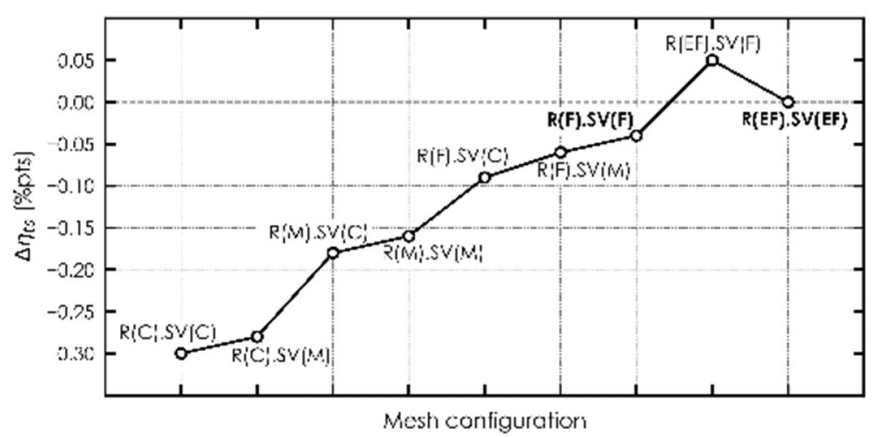

Figure 7 - Grid study efficiency comparison

In addition to the steady-state single passage models, additional numerical analysis was performed on selected vanes at the off-design point to evaluate if the mixing plane interface provided an accurate representation of the turbine performance. The additional analysis was conducted in two stages. The first state consisted of steady-state simulations with a multiple reference frame interface between the stator and rotor. The second stage involved unsteady simulations with a transient rotor-stator interface. To minimise the influence of the relative position of the stator vane and rotor blade on the results, a case with a full $360^{\circ}$ configuration for each component was considered. As the number of stator vanes and rotor blades did not possess a common factor, this method provided an indication of the performance for several different relative positions of the stator and rotor. After completing the steady-state analysis with the full $360^{\circ}$ components, unsteady simulations were conducted, 
which maintained the same full $360^{\circ}$ modelling approach. To ensure a high level of confidence in the results and maintain consistency, the grid independent meshes used in the steady state analysis were also used in the unsteady configurations.

\section{NUMERICAL MODEL VALIDATION}

The results from the grid independent numerical model were compared with experimental test data for the baseline vane configuration. The variation in measured parameters relative to the CFD values is presented in Table 3. A comparison of the numerical and experimental efficiency values is presented in Figure 8 , with the off-design and design points labelled as ' $A$ ' and ' $\mathrm{B}$ ', respectively. A comparison of the MFP characteristics is provided in Figure 9.

The experimental and numerical efficiencies achieved good agreement and followed similar trends. The largest variation was observed at the lower speed line and the variation increased as the pressure ratio across the turbine decreased. The largest discrepancies in efficiency are expected under these conditions as the mean flow velocity through the system is lower increasing the time for heat transfer to occur. This creates an artificially low exit temperature that results in a higher efficiency value. At these conditions the temperature drop across the system is also smaller and any heat transfer from the flow will have a more pronounced impact on the calculated efficiency value. Although every step was taken to thermally insulate the system, some levels of heat transfer are unavoidable.

The experimental results recorded a lower MFP compared to the numerical values. The difference was relatively constant across the operating range, with a variation of $3.4 \%$ at the design and off-design points. The difference was attributed primarily to the presence of blade fillets on the experimental rotor, which were not present in the CFD model. The blade fillets reduced the cross-sectional area of the rotor exducer throat, limiting the flow capacity of the system.

Measurements of the flow field across the rotor outlet taken with a five-hole probe at the off-design point are presented in Figure 10. A good level of agreement was achieved between the measured and CFD values. This indicated that the simulation was predicting the global performance values as well as the local flow features with a good level of accuracy.

Table 3 - Comparison of experimental and CFD efficiency values

\begin{tabular}{lc}
\hline \hline \multicolumn{1}{c}{ Parameter } & Variation from CFD \\
\hline Efficiency (Design point) & $+0.05 \%$ points \\
Efficiency (Off-design point) & $+1.81 \%$ points \\
\hline \hline
\end{tabular}

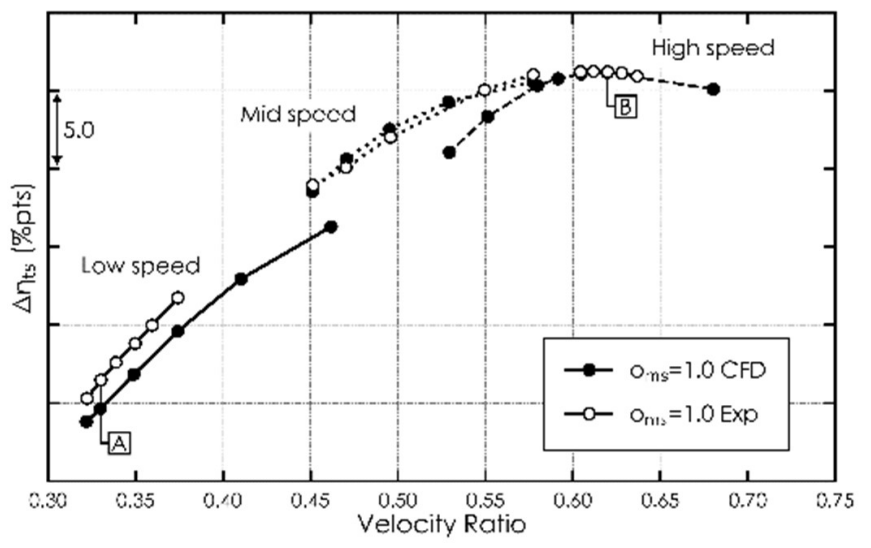

Figure 8 - Experimental and CFD efficiency

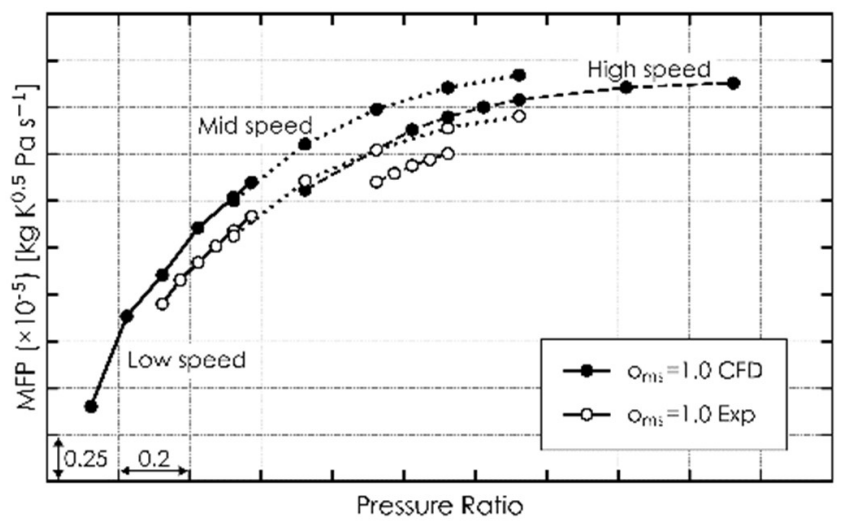

Figure 9 - Comparison of experimental and CFD MFP

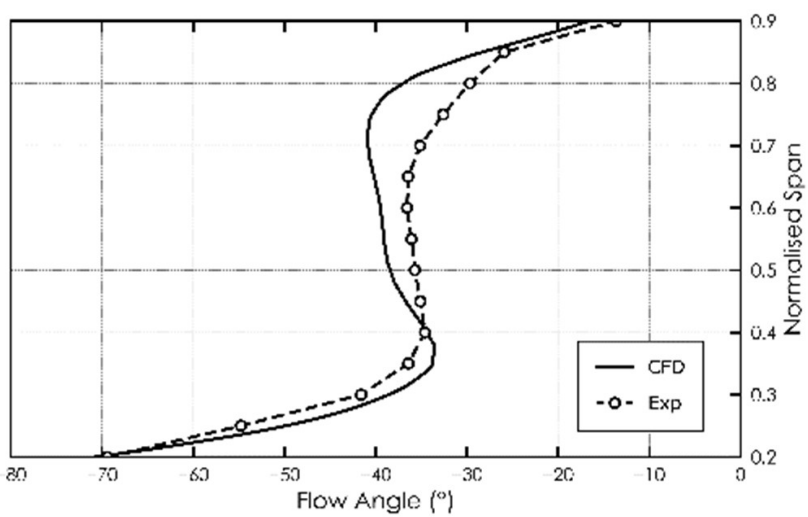

Figure 10 - Flow angle at rotor outlet

\section{STATOR VANE DESIGN}

In the practical application of waste-gate turbochargers the flow conditions at the turbine rotor inlet are determined by the volute. However, for this study the required spanwise distributions of flow angle at rotor inlet were generated with sets of custom stator vanes. The role of the stator vanes was to take the uniform flow field created by the pre-swirl vanes and impart a spanwise variation of flow angle.

This study examined a number of different spanwise flow distributions. The primary aim was to investigate the impact on 
hub side incidence angle by reducing the flow angle in this region, where the flow angle is measured relative to the meridional direction. For completeness, the effects of decreasing the flow angle at the shroud were also considered. A case with uniform flow angle distribution across the span was used as the baseline case. In total 12 different flow distributions were examined, two with a reduced flow angle at the shroud, one uniform baseline case and nine with a reduced flow angle towards the hub.

For a stator vane the exit flow angle $\left(\alpha_{1}\right)$, taken from the meridional direction, is related to the vane throat width $(o)$ and spacing $(s)$, as defined in Figure 11. A reasonable approximation of $\alpha_{1}$ can be obtained by applying the cosine rule, Eq. (2). For a fixed vane spacing, the flow angle can be reduced by increasing the throat size. Therefore, different spanwise distributions of flow angle were produced by leaning the vanes across the span to vary the width of the throat. A consequence of this method was that as the width of the throat changed, so did the distribution of mass flow rate across the span. This was an unavoidable consequence of varying the flow angle.

For a valid comparison it was important that the operating point and MFP of the system did not vary between the cases as a consequence of the changing stator vane design. It was therefore important that each vane configuration had the same total geometric throat area. This was achieved by constraining the throat width at mid-span to the same fixed value for every case. As the throat was increased towards one side of the passage, it was decreased by an equal amount towards the other. The total throat area was defined as that necessary to produce a nominal outlet flow angle equivalent to that of a state-of-the-art wastegate turbocharger volute. To allow for comparison between the different cases, a naming convention was adopted to refer to the different vane configurations. The vanes were referred to by the ratio of the throat width at the hub $\left(\mathrm{o}_{\mathrm{h}}\right)$ to the common mid-span throat width $\left(\mathrm{o}_{0.5}\right)$, which was the same for every case. This ratio was termed the 'hub throat opening ratio' of the stator $\left(\mathrm{o}_{\mathrm{ms}}\right)$, which can be calculated from Eq. (3). For example, the width of the throat next to the hub wall of vane configuration $\mathrm{o}_{\mathrm{ms}}=1.2$ was $20 \%$ larger than the nominal mid-span throat width. This was matched by a $20 \%$ reduction in throat width next to the shroud wall, maintaining the same total throat area as the baseline case.

To limit the number of different parameters examined, the study only considered linear distributions of throat width across the span. The vane hub throat ratio was increased in steps of 0.1 from 0.8 and 1.9. A vane hub throat ratio of two or greater was not geometrically possible as it would result in zero or negative throat width at the shroud.

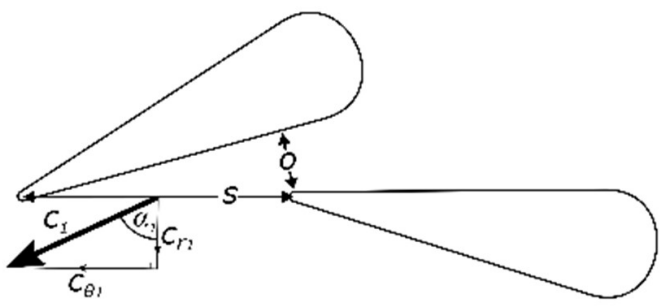

Figure 11 - Stator vane parameters

$$
\begin{aligned}
& \cos \alpha_{1}=\frac{o}{s} \\
& o_{m s}=\frac{o_{h}}{o_{0.5}}
\end{aligned}
$$

As the aim of the study was to examine the impact of different spanwise flow distributions on the performance of a MFT, and not the effectiveness of specific vane designs, it was necessary to ensure variations in vane performance were minimised. Therefore, the vane design focused on producing a relatively constant stator loss coefficient between configurations, and not minimising the loss coefficient for each case.

An uncambered vane design was selected as it reduced the number of variables that could impact the loss coefficient of the different vane designs. To ensure that other factors, such as the vane profile or the flow 'wetted area', did not impact the loss coefficient between the different cases, the cross-sectional vane profile was constant across the span. The required spanwise variation of throat width was produced by rotating the vane about a fixed point. This was similar to varying the vane setting angle across the span. The vane was rotated about the centre of the trailing edge, which maintained the same trailing edge pitch centre diameter across the span for all cases. This was beneficial as the ratio of vane trailing edge pitch radius to the rotor leading edge radius $\left(\mathrm{R}_{\mathrm{TE}} / \mathrm{r}_{\mathrm{LE}}\right)$ has a significant impact on stage performance [17]. Therefore, maintaining the same spanwise $\mathrm{R}_{\mathrm{TE}} / \mathrm{r}_{\mathrm{LE}}$ profile for each case would prevent this factor from influencing the results. The drawback of this approach was that as the vane profile was rotated, the incidence on the vane leading edge varied. This could produce regions of leading edge separation, which are also a significant source of loss for stator vanes [18]. To minimise the extent of separation that may occur, a large leading edge radius was used in the vane design as it was more tolerant of different levels of incidence. The required vane throat distribution for each case was created by defining the vane setting angle at three locations, hub, mid-span and shroud, and creating a linear distribution between these vane profiles. The finalised vane geometries for the baseline case $\left(\mathrm{o}_{\mathrm{ms}}=1.0\right)$ and vane configuration $\mathrm{o}_{\mathrm{ms}}=1.4$ are illustrated in Figure 12 and Figure 13, respectively.

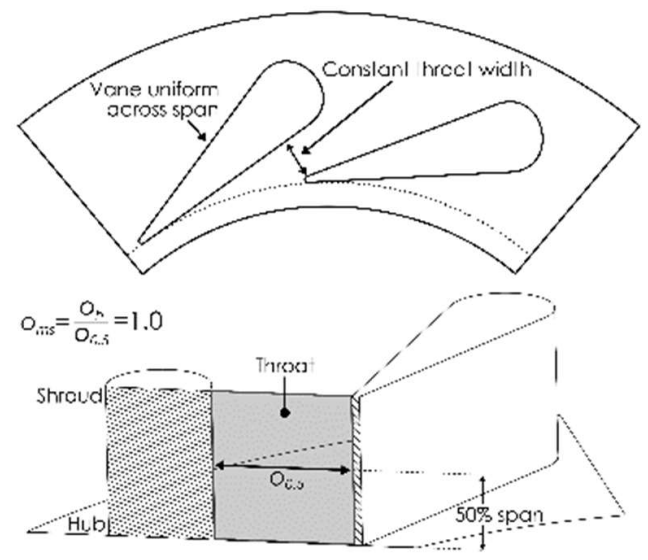

Figure 12 - Baseline stator vane $\left(o_{m s}=1.0\right)$ 

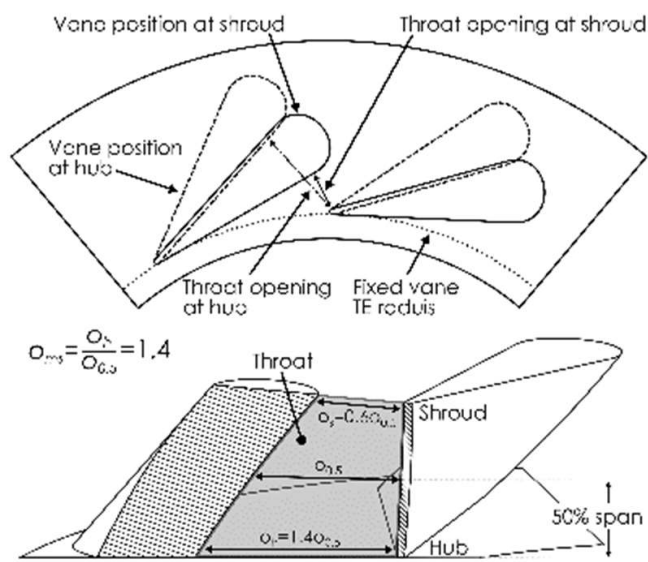

Figure $13-\mathrm{oms}_{\mathrm{ms}}=1.4$ Stator vane

\section{STATOR VANE ANALYSIS}

To evaluate the performance variation between the different stator vane configurations, each configuration was simulated without a turbine downstream. This was achieved by replacing the rotor with a stationary flow passage with the same hub and shroud profiles. The upstream pre-swirl vanes were included to ensure that the impact of flow alignment at the vane leading edge was captured. This analysis was conducted to determine if changes to stage performance were due to the variation in rotor inlet flow conditions or different levels of stator loss.

An important aim of the stator vane design was to ensure that the total mass flow rate did not vary significantly between vane configurations. For the 12 vanes examined, the mass flow rate was found to slightly increase with the hub throat opening ratio. The maximum change in mass flow rate was $+2.1 \%$, this was deemed to be within an acceptable tolerance. The variation of mass flow rate can be attributed to a number of different factors, including different levels of aerodynamic blockage within the passage. Additionally the throat did not occur at the same streamwise position within the vane passage for each case. Instead it moved closer to the leading edge as the hub side throat width increased, as shown in Figure 13, which produced a minor increase in the throat area. The aerodynamic throat area was dependent on a number of factors in the vane passage, including boundary layer blockage and the throat wetted area.

The variation of stator loss coefficient did not correlate directly with the hub throat opening ratio. For ratios under 1.2 the loss coefficient varied by less than $1.5 \%$. However, above this ratio the loss coefficient varied to a larger extent. The maximum variation was an increase of $16 \%$ for the $\mathrm{o}_{\mathrm{ms}}=1.9$ case relative to the baseline. The increase in stator loss was primarily the result of misalignment between the flow and the vane close to the shroud. The highly tangential angle of the vane in this region produced a large negative incidence angle at the vane leading edge. This resulted in a vortex forming close to the shroud on the vane pressure surface which travelled downstream through the vane passage and mixed with the trailing edge wake. The $\mathrm{o}_{\mathrm{ms}}=1.9$ case also experienced a larger trailing edge wake at both the shroud, due to the flow misalignment, and the hub due to higher flow velocity. A comparison of the trailing edge wakes for the baseline and $\mathrm{o}_{\mathrm{ms}}=1.9$ cases at $97 \%$ span is provided in Figure 14. There was also additional loss due to secondary flow occurring in the spanwise direction, caused by the variation of flow conditions across the span. The substantial spanwise variation of vane angle required meant that an increased stator loss coefficient was unavoidable. The impact of the variation in stator loss coefficient could be partly accounted for by considering the efficiency only across the rotor.

Examination of the flow conditions at a measurement plane downstream of the vane trailing edge, illustrated in Figure 14, revealed that sufficient spanwise variations of flow angle were produced by the different vane configurations. As intended the flow angle, taken from the meridional direction, reduced as the throat width increased. It was noted that the baseline case, with a uniform vane profile, produced a small increase in flow angle towards the hub of approximately $+2^{\circ}$, and a reduction of $-2^{\circ}$ at the shroud, relative to the average value. This resulted from the rapid flow turning in the meridional direction that occurred close to the shroud side just after the vane outlet, which was not present at the hub. The most uniform flow angle distribution was produced by the $\mathrm{o}_{\mathrm{ms}}=1.1$ case, where the increased throat size towards the hub acted to counteract the variation observed in the baseline case. When the flow field was examined close to the hub, the flow angle was found to vary linearly with hub throat opening ratio. The flow angle produced at $10 \%$ span for each case is presented in Figure 15. The largest variation at $10 \%$ span was observed for the $\mathrm{O}_{\mathrm{ms}}=1.9$ case, which had a reduction in flow angle of $10.3^{\circ}$ from the nominal value and $12.3^{\circ}$ from the baseline case.
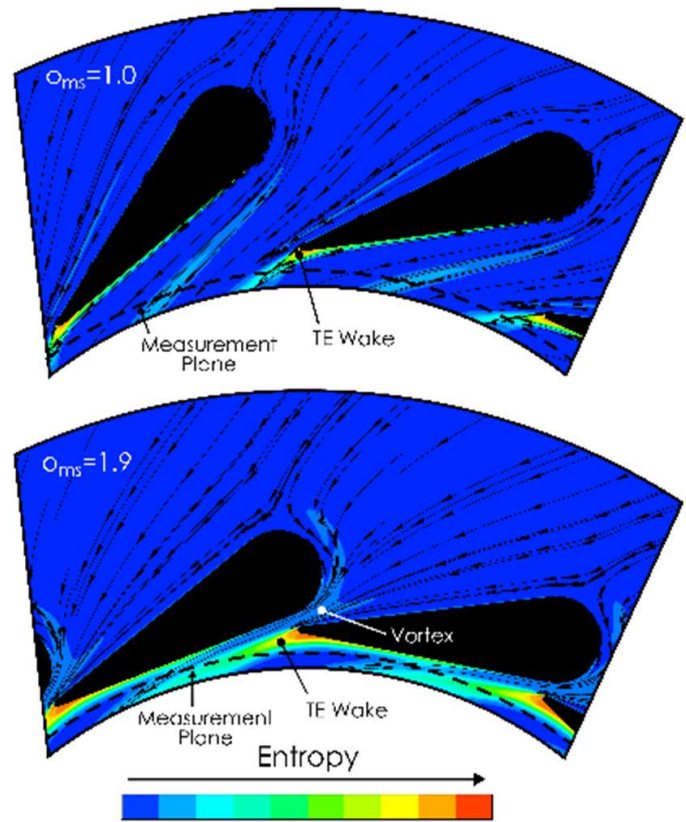

Figure 14 - Entropy at $97 \%$ span for $o_{m s}=1.0$ (top) and $\mathrm{O}_{\mathrm{ms}}=1.9$ (bottom) vanes 
An important parameter considered at vane outlet in addition to flow angle was the radial flow velocity, as this was proportional to mass flow rate. The spanwise variation of radial flow velocity, normalised against the average radial flow velocity of the baseline case, is presented in Figure 16. The maximum variation achieved was an increase of $57 \%$ which occurred at $2 \%$ span for the $\mathrm{o}_{\mathrm{ms}}=1.9$ case. The results indicated that as the hub throat opening ratio was increased, a greater portion of the total mass flow was biased towards the hub and away from the shroud side of the passage. This was an inevitable consequence of decreasing the absolute flow angle near the hub.

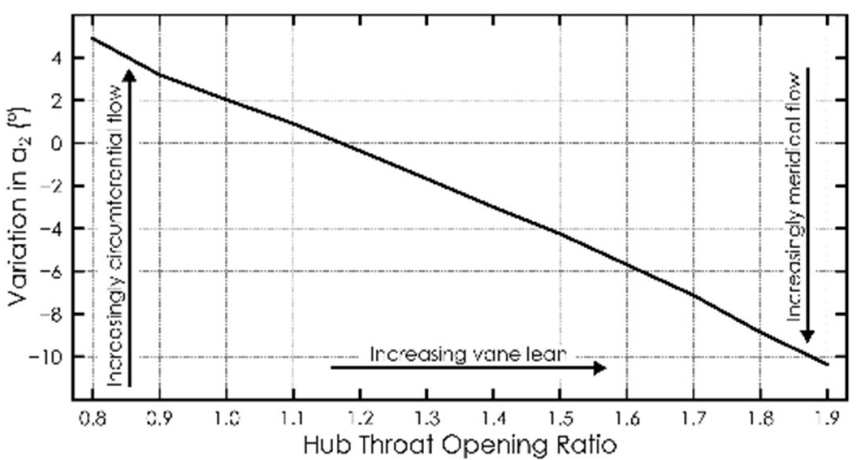

Figure 15 - Variation of vane flow angle at $10 \%$ span

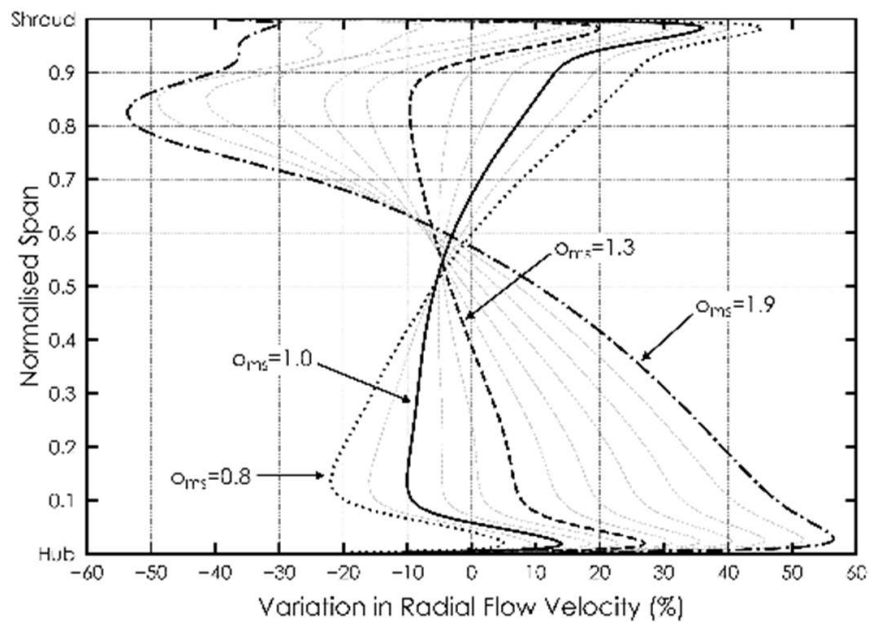

Figure 16 - Variation of radial velocity at stator outlet

\section{RESULTS}

\section{Design condition performance}

The turbine was examined at a high rotational speed with a $U / C$ of 0.63 , to represent operation close to the design point. The uniform stator vane case $\left(\mathrm{o}_{\mathrm{ms}}=1.0\right)$, was used as a baseline to compare the performance of the other cases against.

The total-to-static turbine stage efficiency for each vane configuration normalised against the baseline case for each operating point is presented in Figure 17. From Figure 17 it can be observed that the efficiency increased with vane hub throat opening ratio, indicating that reducing the flow angle and increasing the portion of mass flow towards the hub was beneficial at the design point. The $\mathrm{o}_{\mathrm{ms}}=1.9$ case achieved the largest improvement in stage total-to-static efficiency relative to the baseline case with an increase of +2.5 percentage points. When the total-to-static efficiency was calculated between rotor inlet and diffuser outlet, to discount the changes in stator loss coefficient, the efficiency increased to 3.2 percentage points for the $o_{\mathrm{ms}}=1.9$ case, relative to the baseline value. Each of the configurations with a ratio greater than 1.0 , experienced an efficiency improvement compared to the baseline.

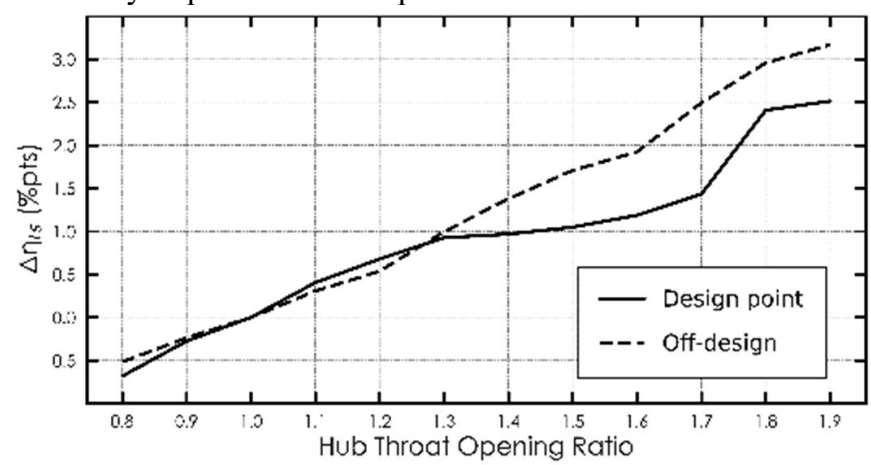

Figure 17 - Variation of efficiency with vane configuration

\section{Off-design performance}

The turbine was examined at a low $U / C$ of 0.33 to represent off-design operation, typically characterized by strong positive incidence and significant suction surface flow separation. This operating point corresponded to a reduction in rotational speed to $44 \%$ of the design condition speed and a decrease in pressure ratio across the turbine. Substantial efficiency improvements were achieved compared to the design point due to the highly positive incidence angle of the baseline case at off-design. The $\mathrm{o}_{\mathrm{ms}}=1.9$ case achieved the largest efficiency improvement compared to the baseline case, with an increase of 3.2 percentage points. Compared to the design point, the efficiency did not appear to plateau at the larger hub throat opening ratios. This implied that greater benefit could be gained by further reducing the flow angle towards the hub. This could be achieved, while still maintaining a throat opening at the shroud, by using a nonlinear distribution of throat width across the span.

As the $\mathrm{o}_{\mathrm{ms}}=1.9$ vane configuration achieved the best performance at both operating conditions, it was selected along with the baseline vane for further numerical analysis and experimental testing. The efficiency values obtained from the additional numerical analysis at the off-design point are presented in Table 4 relative to the values obtained with the single passage mixing-plane approach. For both vane configurations, the steady-state multiple reference frame interface and the unsteady simulations showed negligible discrepancy. Compared to the mixing plane model, the baseline case had an efficiency increase of approximately $0.57 \%$ points and the $\mathrm{O}_{\mathrm{ms}}=1.9$ case had a reduction in efficiency of $0.28 \%$ points. This resulted in a reduction of the improvement for the $\mathrm{o}_{\mathrm{ms}}=1.9$ case from $3.2 \%$ points to $2.3 \%$ points. 
Table 4 - Efficiency variation at off-design

\begin{tabular}{lcc}
\hline \hline \multicolumn{1}{c}{ Method } & \multicolumn{2}{c}{$\begin{array}{c}\text { Efficiency relative to single } \\
\text { passage model (\% points) }\end{array}$} \\
& $\mathrm{O}_{\mathrm{ms}}=1.0$ & $\mathrm{O}_{\mathrm{ms}}=1.9$ \\
\hline $\begin{array}{l}\text { Multiple reference } \\
\text { frame steady state }\end{array}$ & +0.59 & -0.29 \\
Unsteady CFD & +0.57 & -0.28 \\
Experimental & +1.81 & +1.23 \\
\hline \hline
\end{tabular}

Experimental testing was conducted for the baseline and $\mathrm{o}_{\mathrm{ms}}=1.9$ vane configurations across three different operating speeds to represent a turbine map. The experimental results confirmed that the $\mathrm{O}_{\mathrm{ms}}=1.9$ configuration achieved a performance improvement over the baseline vane at all operating points, including an increase of $2.6 \%$ points at the off-design condition and $2.0 \%$ points at the design condition. A comparison of the CFD and experimental efficiency values for both vane configurations is presented in Figure 18. The MFP characteristic for the $\mathrm{o}_{\mathrm{ms}}=1.9$ vane is presented in Figure 19. A similar reduction in MFP was observed for the $\mathrm{O}_{\mathrm{ms}}=1.9$ case as for the baseline vane.

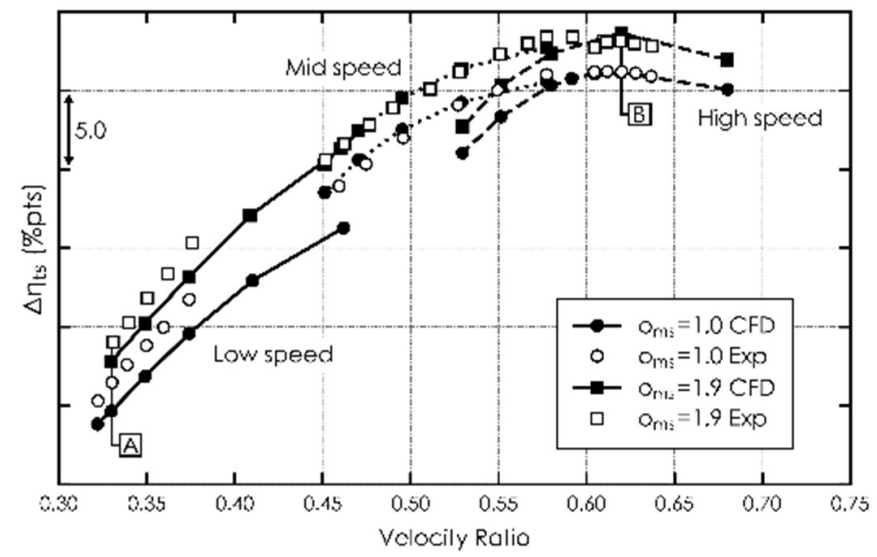

Figure 18 - Efficiency comparison for $\mathrm{O}_{\mathrm{ms}}=1.0$ and $\mathrm{O}_{\mathrm{ms}}=1.9$

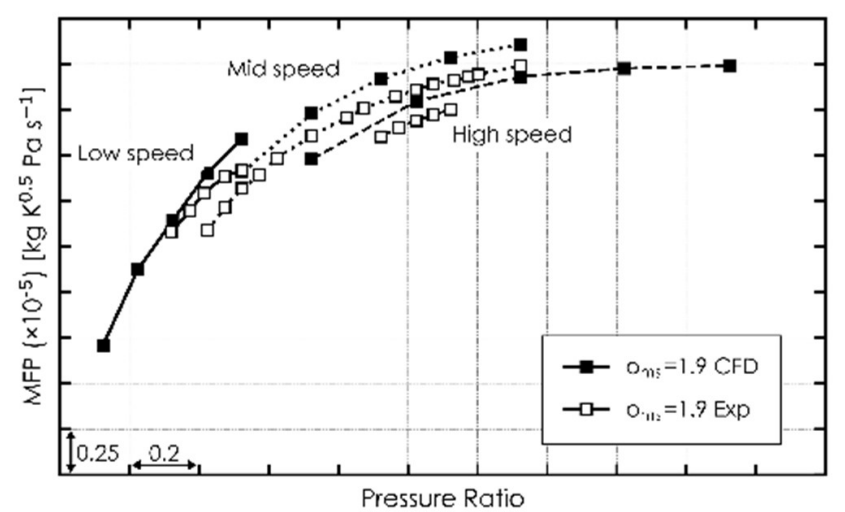

Figure 19 - MFP comparison for $o_{m s}=1.9$

\section{DISCUSSION}

\section{Design condition performance}

The improvement in stage efficiency at the design point correlated with an increasingly uniform distribution of incidence angle across the leading edge, as illustrated in Figure 20. For the baseline case the average incidence angle was $-6^{\circ}$, which was typical for this operating condition. However, due to the change in tip radius across the leading edge, the incidence angle varied by $55^{\circ}$ from $-26.6^{\circ}$ at $95 \%$ span to $+28.6^{\circ}$ at $12 \%$ span. Towards the hub side of the passage, the flow experienced a large region of separation from the blade suction surface, as shown in Figure 21 . This separation was not present above $50 \%$ span where the incidence angle was negative. This confirmed that even at the design point, a MFT with a uniform flow distribution upstream of the inlet can still experience significant positive incidence close to the hub, resulting in flow separation and increased passage loss.

For the non-uniform vane configurations, the incidence angle near the hub reduced as the hub throat opening ratio increased. For the peak efficiency configuration, $\mathrm{o}_{\mathrm{ms}}=1.9$, the maximum incidence angle near the hub was $+11.1^{\circ}$, a reduction of $17.5^{\circ}$ compared to the baseline. Towards the shroud, the incidence angle increased with hub throat opening ratio. However, the extent of the change was not as significant as at the hub and the incidence angle remained negative in this region for all cases. This resulted in no flow separation close to the shroud for every case, since the incidence angle was within the optimum range. The combination of these factors resulted in a more uniform spanwise flow angle distribution across the leading edge for the $\mathrm{o}_{\mathrm{ms}}=1.9$ case compared to the baseline, as illustrated in Figure 20.

Separation from the blade suction surface near the hub was observed for all cases. The separation originated immediately after the leading edge. As it progressed downstream it formed a vortex and moved up the blade surface towards the shroud before mixing with the tip leakage vortex (TLV). For the $o_{\mathrm{ms}}=1.9$ case the size and intensity of the separation was significantly reduced compared to the baseline case, as shown in Figure 21. The separation which did occur followed a similar path to that of the baseline case. For both cases the vortex formed by the separation had the same rotational direction as the TLV and mixed with it near the blade trailing edge. A comparison of the size of the resulting vortex at $90 \%$ blade chord is illustrated in Figure 22. Additional shaping of the flow to further improve the incidence angle close to the hub could potentially eliminate this separation, providing an additional performance improvement. 


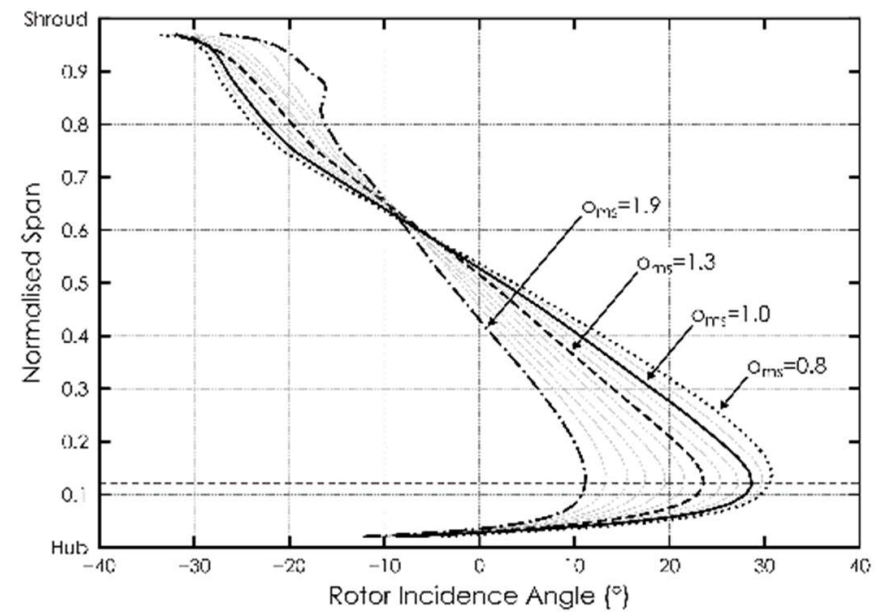

Figure 20 - Design point rotor incidence angle

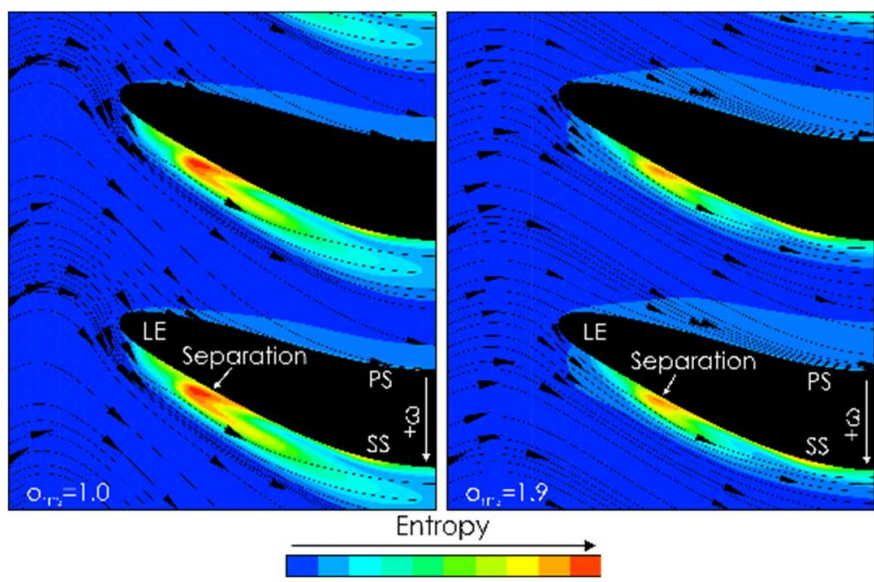

Figure 21 - Entropy at $10 \%$ span for $o_{m s}=1.0$ (left) and $\mathrm{O}_{\mathrm{ms}}=1.9$ (right) at the design point

The spanwise distribution of radial flow velocity at the outlet of each vane followed a similar trend to that shown in Figure 16. Therefore, as the hub throat ratio increased, a greater portion of mass flow was shifted towards the hub side of the passage, and away from the shroud and tip gap region. The $\mathrm{o}_{\mathrm{ms}}=1.9$ case had a higher incidence angle towards the shroud which caused greater blade loading in this region and increased the tip leakage flow close to the leading edge. However, this was offset by the reduced mass flow rate in this region and downstream of $15 \%$ blade chord the blade loading of the baseline case exceeded that of the oms $=1.9$ case. The reduced mass flow rate also reduced the size of the vortex that resulted from the relative motion of the shroud wall.

The impact of the change in tip leakage flow was estimated by examining the rotor with the tip gap interface disabled and the shroud wall set to rotate with the same angular velocity as the rotor. This removed the effects of the tip leakage loss and the relative motion of the shroud. Removing these loss sources increased the efficiency for the baseline case by $9.7 \%$ points and the $\mathrm{o}_{\mathrm{ms}}=1.9$ efficiency by $6.0 \%$ points. Without these loss sources the highest efficiency was achieved with the $\mathrm{o}_{\mathrm{ms}}=1.3$ configuration. The reduced benefit for $\mathrm{o}_{\mathrm{ms}}=1.9$ configuration indicated that at this operating point the primary benefit of varying the spanwise flow distribution is the reduction of the tip leakage loss and the relative motion of the shroud endwall. A larger loss structure was still observed for the baseline case compared to the $\mathrm{o}_{\mathrm{ms}}=1.9$ case close to the shroud at the outlet of the blade passage. This was due to the increased size of the pressure leg of the horse-shoe vortex which travelled across the passage from the adjacent blade as well as the corner vortex from the blade tip. The benefits from these factors and the reduced suction side separation were offset by the higher loss from the stator vanes and the increased trailing edge wake at the hub caused by the higher flow velocities in this region.

The effect of shaping the inlet flow on the TLV and other flow structures is shown in Figure 22. A high region of entropy close to the shroud and blade suction surface is present for both configurations, however the size is greatly reduced for the $\mathrm{o}_{\mathrm{ms}}=1.9$ case. This reduced the loss generated within the flow passage and the size of the aerodynamic blockage at the rotor exducer

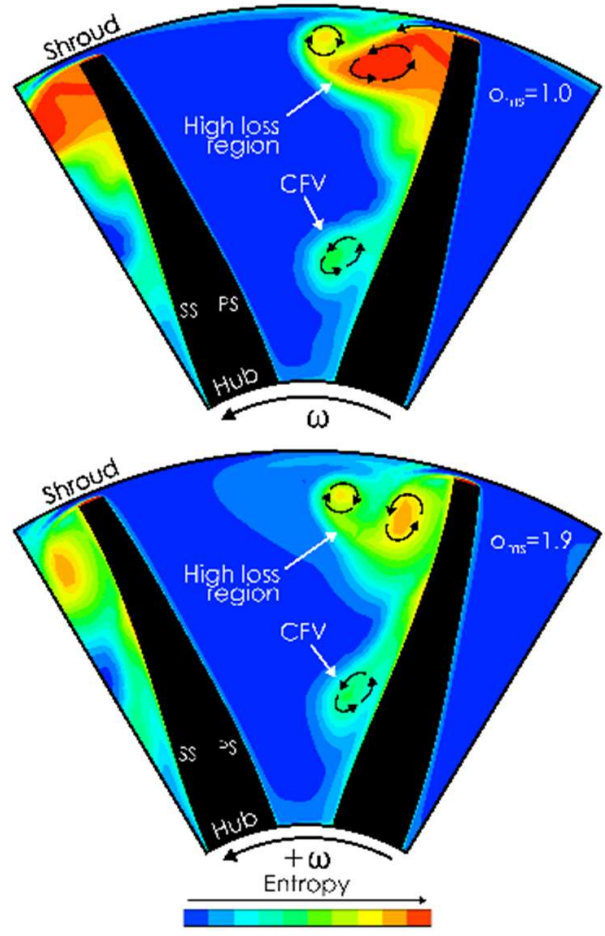

Figure 22 - Entropy at $90 \%$ blade chord for $\mathrm{O}_{\mathrm{ms}}=1.0$ (top) and $\mathrm{O}_{\mathrm{ms}}=1.9$ (bottom) at the design point

\section{Off-design performance}

At the off-design condition the average incidence angle for the baseline case was $+35.6^{\circ}$ and the spanwise distributions of incidence angle for each vane configuration are presented in Figure 23. A positive incidence angle was experienced across the full span for each vane configuration. A similar trend was observed to that at the design point, where the incidence angle 
towards the hub decreased as the hub throat opening ratio increased. The variation of incidence angle between the cases was a result of the change in the spanwise distribution of absolute flow angle at the stator vane outlet. The variation of relative flow angle in the vanless space at rotor inlet compared to the average value at the stator vane to rotor interface for the baseline and $\mathrm{o}_{\mathrm{ms}}=1.9$ cases is presented in Figure 24. For the baseline case, the relative flow angle at the shroud side of the leading edge was within $5^{\circ}$ of the reference value. As blade tip radius decreased towards the hub, the relative flow angle increased in excess of $20^{\circ}$ compared to the reference value. This resulted in a maximum incidence angle of $+49.2^{\circ}$ at $12 \%$ span, an increase of $13.6^{\circ}$ compared to the average incidence angle for this case. A similar increase in relative flow angle towards the hub was observed for the $\mathrm{o}_{\mathrm{ms}}=1.9$ case. However, the increase was offset by a lower relative flow angle close to the hub at the inlet to the passage. This resulted in a relative flow angle increase towards the hub side of the leading edge of only $5^{\circ}$ compared to the reference value. At $12 \%$ span this configuration experienced an incidence angle of $+31.8^{\circ}$, a reduction of $17.4^{\circ}$ compared to the baseline case. Additionally, this case also produced the most uniform distribution of incidence angle between the hub and 50\% span, as shown in Figure 23.

The impact of the improved incidence angle on the suction side separation is evident from Figure 25, which compares the static entropy at $10 \%$ span for the baseline and $\mathrm{o}_{\mathrm{ms}}=1.9$ vane configurations. It can be observed that a larger suction side separation occurred in the baseline case. However, the $\mathrm{o}_{\mathrm{ms}}=1.9$ case still produced a small region of high entropy immediately downstream of the leading edge. Analysis of the flow field revealed that this was due to both the positive incidence angle and the presence of the cavity flow vortex (CFV). In contrast to the design point, the higher hub throat opening ratio vanes produced a larger CFV compared to the baseline case. This was the result of an increase in blade loading close to the hub caused by higher flow velocities in this region. This increased the mass flow through the cavity by $15.6 \%$ for the $\mathrm{o}_{\mathrm{ms}}=1.9$ case compared to the baseline, producing a larger CFV.

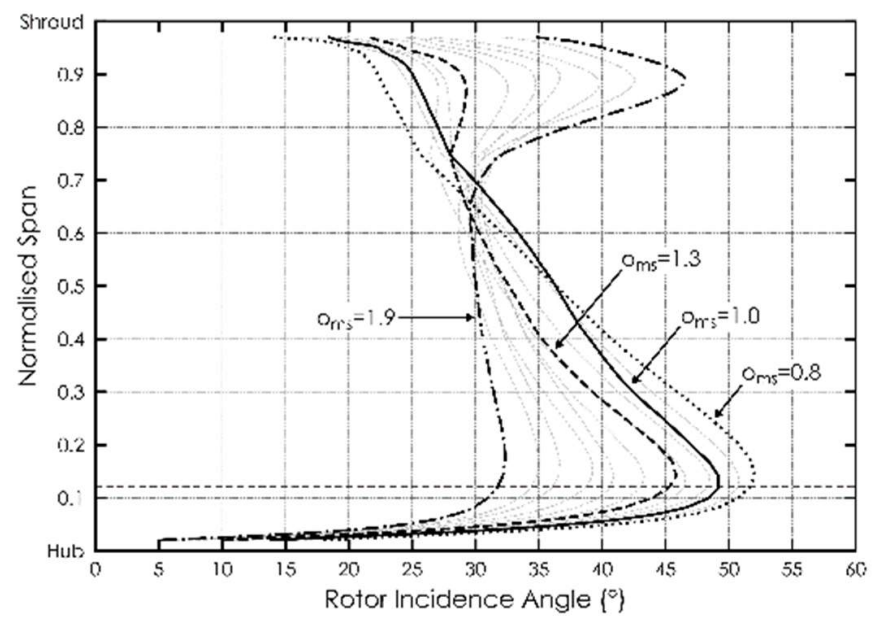

Figure 23 - Off-design rotor incidence

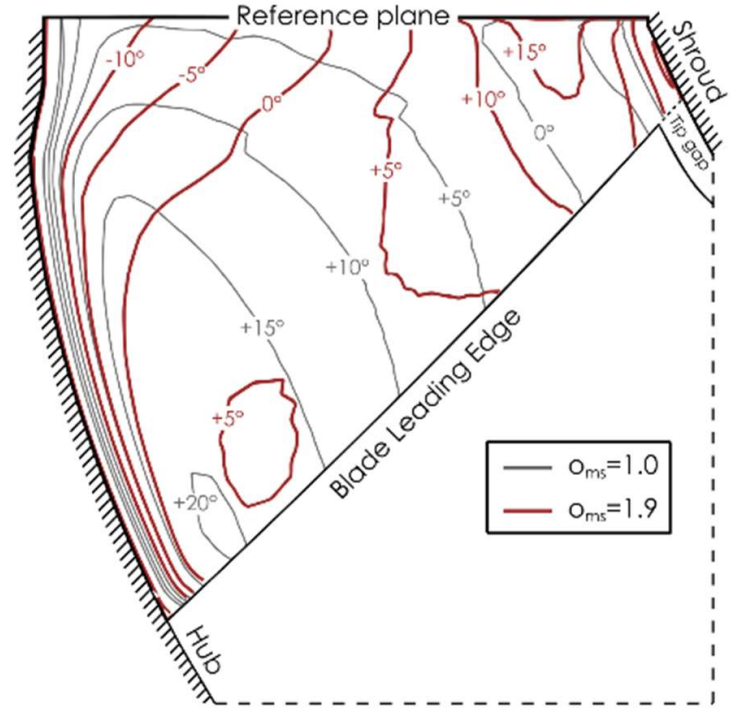

Figure 24 - Variation of relative flow angle for the $O_{m s}=1.0$ and $O_{m s}=1.9$ cases at off-design

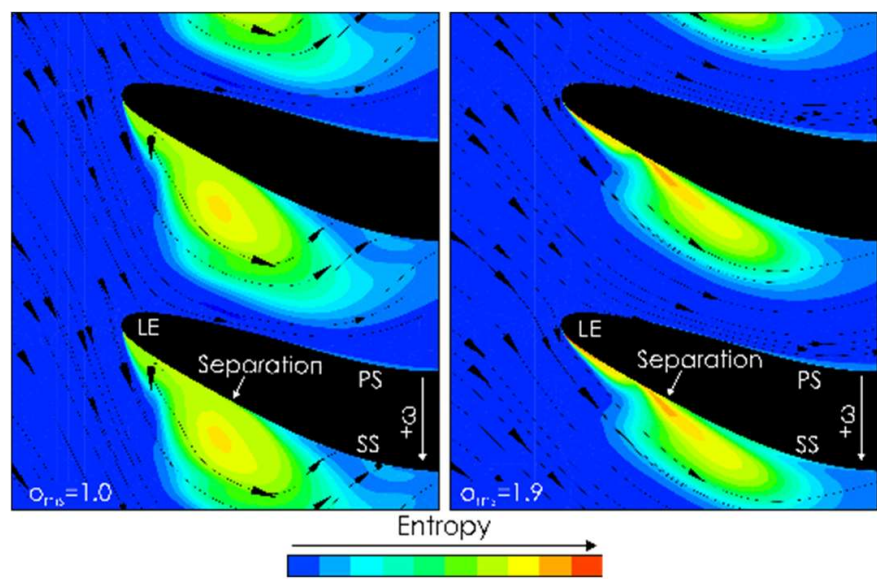

Figure 25 - Entropy at 10\% span for $O_{\mathrm{ms}}=1.0$ (left) and $\mathrm{O}_{\mathrm{ms}}=1.9$ (right) at off-design

In addition to reduced leading edge separation, the size and intensity of the TLV was also reduced as the hub throat opening ratio increased, as illustrated in Figure 26. This was attributed to the reduced mass flow rate on the shroud side of the passage. When the distribution of mass flow was considered at the inlet to the blade passage, $7.24 \%$ of the flow was in the tip gap region for the baseline case, compared to $3.81 \%$ for the $\mathrm{o}_{\mathrm{ms}}=1.9$ case. This resulted in a reduction of the loss associated with the TLV. However, compared to the design point, there was a less significant variation in efficiency achieve by removing the tip leakage flow between the baseline and $\mathrm{o}_{\mathrm{ms}}=1.9$ cases. With the tip leakage flow disabled the $\mathrm{o}_{\mathrm{ms}}=1.9$ case still achieved the highest efficiency of the cases considered. At the rotor trailing edge the baseline case still experienced a high loss region close to the shroud compared to the $\mathrm{o}_{\mathrm{ms}}=1.9$ case. This was attributed primarily to the suction surface separation which had migrated 
up the blade suction surface towards the shroud as it progressed downstream. This indicated that at the off-design point the benefit of the flow shaping was from the reduction of suction side separation and not from the shift in mass flow away from the tip region.

Circumferentially averaged plots of static entropy in the rotor passage for the baseline and $\mathrm{o}_{\mathrm{ms}}=1.9$ cases are presented in Figure 27. Dividing surfaces of revolution (dashed lines) with equal streamwise mass flow rate in the regions above and below the surfaces have been plotted for both cases in Figure 27. For the baseline case the mean mass flow location at inlet was at a normalised span of 0.54 , representing a relatively uniform distribution of mass flow across the span. For the $\mathrm{o}_{\mathrm{ms}}=1.9$ case, the mid mass flow point was at a span of 0.37 , indicating that the majority of the flow was located towards the hub side of the passage. For this case, the mass flow distribution became more uniform progressing along the streamwise direction towards the trailing edge, and had a mean span of 0.49 at the exit of the domain. For the baseline case, as the flow progressed downstream it shifted towards the hub side of the passage. This was due in part to the large aerodynamic blockage caused by the TLV near the trailing edge, as represented in the static entropy plots in Figure 26 and Figure 27. At the exit of the rotor domain, $50 \%$ of the mass flow was located below a span of 0.42 for the baseline case.

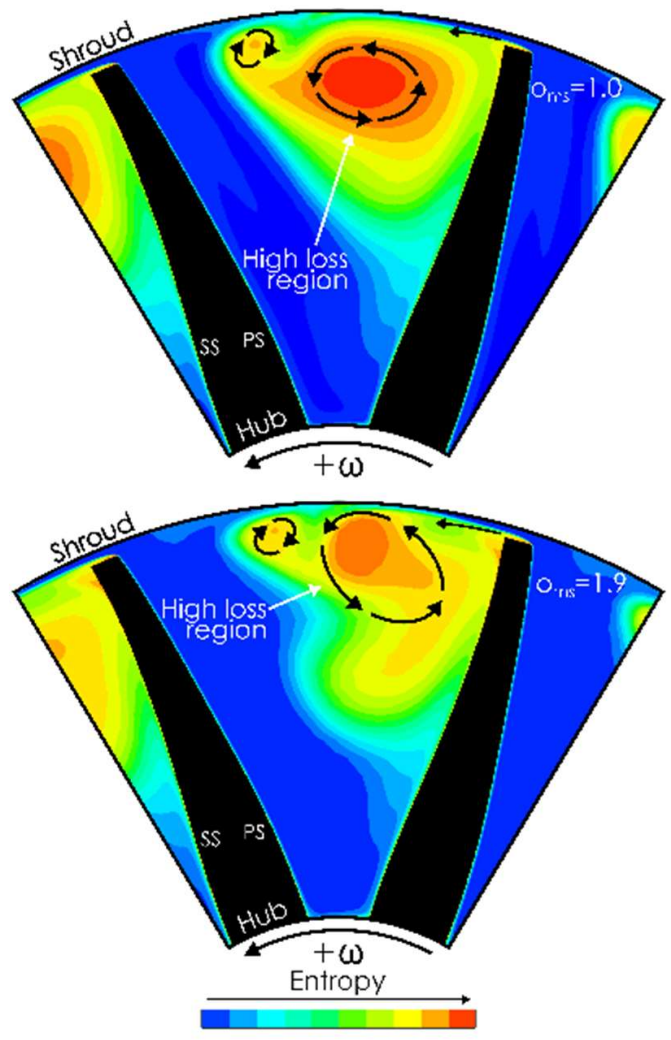

Figure 26 - Entropy $90 \%$ blade chord for $\mathrm{O}_{\mathrm{ms}}=1.0$ (top) and $\mathrm{O}_{\mathrm{ms}}=1.9$ (bottom) at off-design
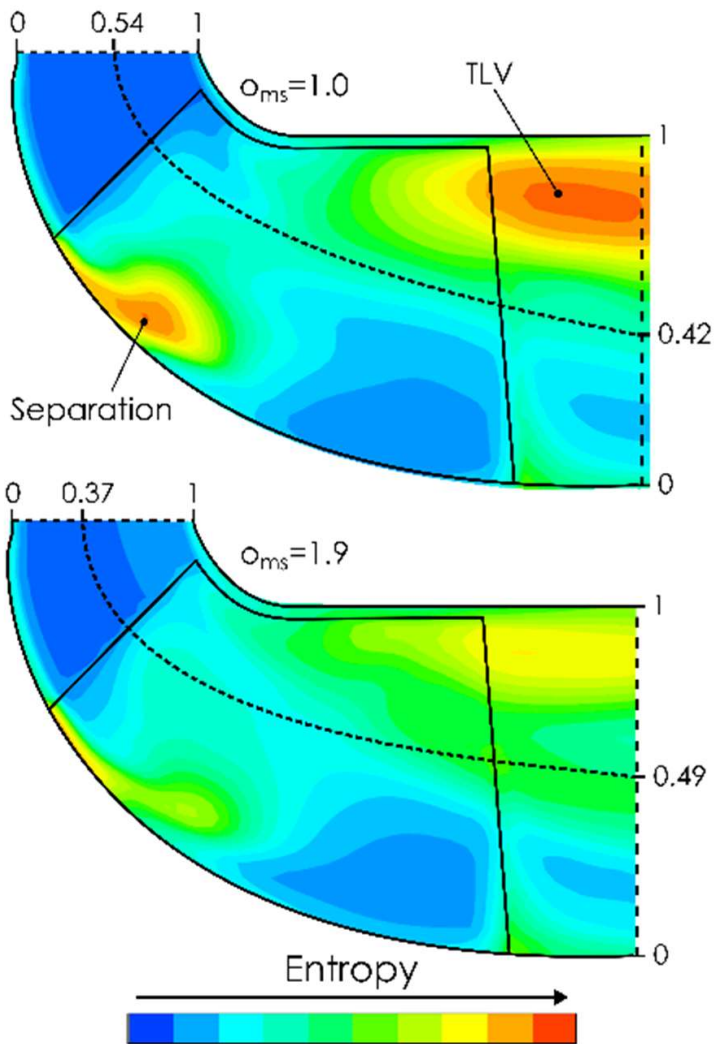

Figure 27 - Circumferentially averaged entropy in the rotor passage for $\mathrm{O}_{\mathrm{ms}}=1.0$ (top) and $\mathrm{O}_{\mathrm{ms}}=1.9$ (bottom)

\section{Performance comparison across turbine map}

Three vane configurations were selected for analysis over a wider range of operating conditions. The $\mathrm{o}_{\mathrm{ms}}=1.0$ case was selected as a baseline, the $\mathrm{o}_{\mathrm{ms}}=1.9$ was selected as it produced the largest improvement, and the $\mathrm{o}_{\mathrm{ms}}=1.3$ case was selected as an intermediate point. Each configuration was considered across three speed lines corresponding to low (off-design), medium (78\% of design speed) and high (design) turbine operating speeds.

The variation of total-to-static stage efficiency from preswirl vane inlet to diffuser outlet with velocity ratio for each vane configuration is presented in Figure 28. For all operating conditions considered, the efficiency increased with the vane hub throat opening ratio, with the $\mathrm{o}_{\mathrm{ms}}=1.9$ case achieving the highest efficiency for each operating point. The largest efficiency improvement relative to the baseline was an increase of 5.0 percentage points for the $\mathrm{o}_{\mathrm{ms}}=1.9$ case at a velocity ratio of 0.46 at the lowest rotational speed. For the highest rotational speed, the largest benefits were achieved between velocity ratios of 0.58 and 0.63 . As the velocity ratio increased towards 0.7 , the $\mathrm{o}_{\mathrm{ms}}=1.9$ case still provided an improvement, however the extent of the improvement became less significant. This was due to a lower average incidence angle for the baseline case which approached the optimum range. The benefit of the flow shaping was therefore found to be more significant at off-design operation. At velocity ratios above 0.7 , larger hub throat opening ratio vanes 
may reduce performance as the incidence may become excessively negative at the hub.

The total-to-static rotor efficiency, measured between the rotor inlet and a plane located one blade tip radius downstream of the trailing edge, is presented in Figure 29. This allowed the variation in rotor performance to be considered without the influences of the stator vanes and exhaust diffuser. Compared to the stage efficiency improvements, a greater benefit was observed for the $\mathrm{o}_{\mathrm{ms}}=1.3$ and $\mathrm{o}_{\mathrm{ms}}=1.9$ cases at the low and medium speed operating points. The largest improvement in rotor efficiency was achieved at the same operating point as the stage efficiency, however, the benefit increased by 1.6 percentage points to 6.6 percentage points. At the high operating speed the efficiency improvement achieved across the rotor was less significant compared to the full stage measurements, with an average improvement of 1.3 percentage points compared to 2.0 for the full stage measurements.

The MFP characteristics of the three vane configurations are presented in Figure 30. The MFP for a given pressure ratio was found to increase with vane hub throat opening ratio. This was attributed in part to the improved turbine efficiency and the resulting reduction in secondary flow and aerodynamic blockage.

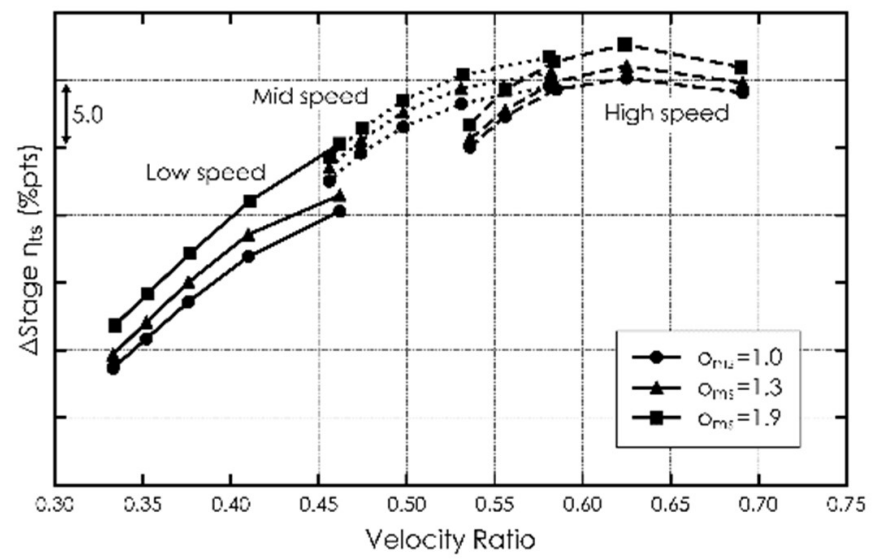

Figure 28 - Stage efficiency comparison

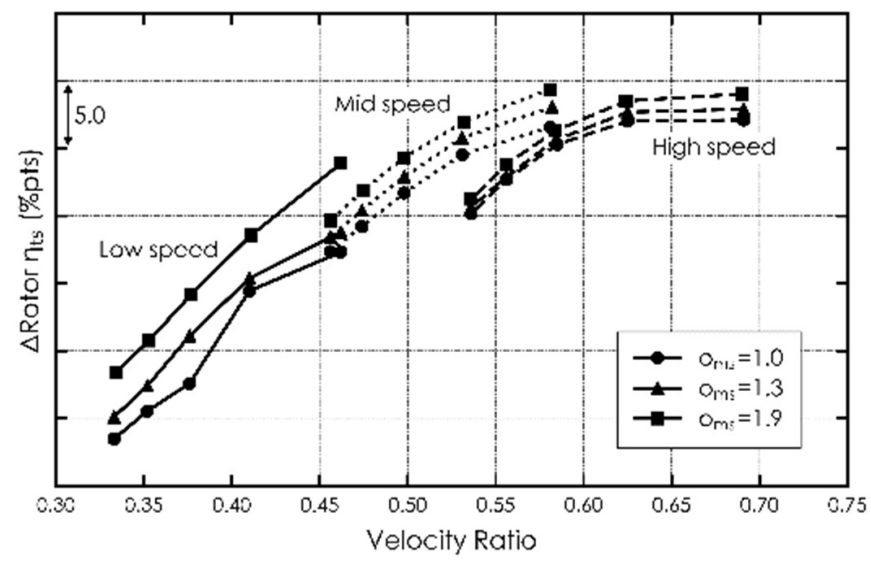

Figure 29 - Rotor efficiency comparison

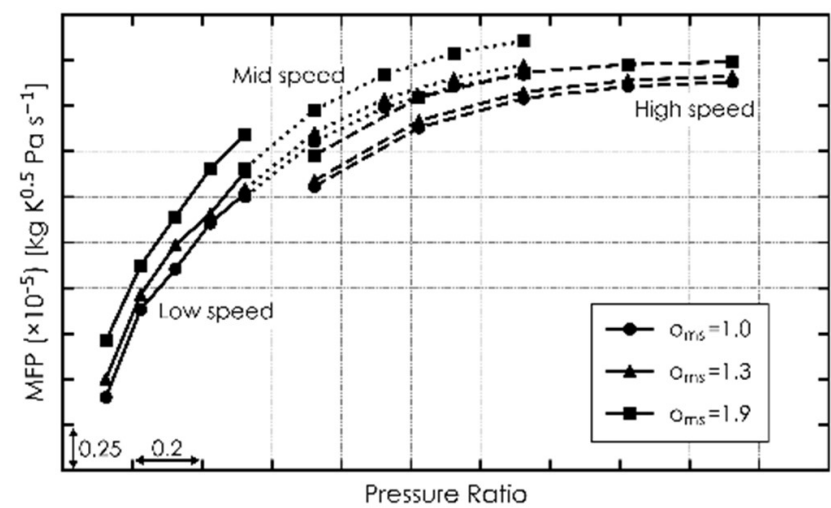

Figure 30 - Mass flow characteristic comparison

\section{CONCLUSIONS}

The aim of this study was to determine if the losses in a MFT could be reduced by deliberately creating a significant spanwise variation of flow angle between hub and shroud at rotor inlet. A series of leaned stator vanes were produced for this study and examined computationally using a validated CFD model. The leaned stator vanes were examined at two distinct operating conditions: a high efficiency 'design' point and a low velocity ratio 'off-design' point. The performance of each vane was compared with that of a straight baseline vane. The CFD results showed that at both operating conditions the turbine performance increased as the vane lean increased. The vane with the most significant lean produced the highest turbine stage efficiency improvement compared to the baseline vane, with an increase of 3.2 percentage points at the off-design condition. Additional CFD analysis of selected vanes across three speed lines indicated a performance advantage for the leaned vanes at all operating points.

Experimental testing of the baseline vane and the vane with the greatest lean confirmed the improved performance of the leaned vane at all operating conditions with a measured efficiency improve of 2.6 percentage points at the off-design point. Both the CFD and experimental results demonstrate the potential advantage of designing the stator vane to manage the inlet flow field of a MFT.

The CFD model was further validated through experimental flow field measurements at rotor exit. The CFD model was used to gain a physical understanding of how the loss generating mechanisms within the rotor were modified as the inlet flow field was adjusted using the leaned vanes. The primary improvements to the flow field were reduced separation from the blade suction surface close to the hub and shift in mass flow away from the shroud and towards the hub, reducing tip leakage loss.

\section{NOMENCLATURE}

$\mathrm{C} \quad$ Isentropic spouting velocity

$\mathrm{C}_{1} \quad$ Velocity at stator outlet

$\mathrm{C}_{\mathrm{r} 1} \quad$ Radial velocity at stator outlet

$\mathrm{C}_{\Theta 1} \quad$ Circumferential velocity at stator outlet

o Vane throat 
$\mathrm{o}_{0.5} \quad$ Vane throat at $50 \%$ span

$\mathrm{O}_{\mathrm{h}} \quad$ Vane throat at hub side

$\mathrm{O}_{\mathrm{ms}} \quad$ Vane hub throat opening ratio

$\mathrm{r}_{\mathrm{TE}} \quad$ Vane trailing edge tip radius

$\mathrm{R}_{\mathrm{LE}} \quad$ Blade leading edge tip radius

S Vane spacing

U Blade tip velocity

$\alpha_{1} \quad$ Vane outlet flow angle

$\beta_{\mathrm{b}} \quad$ Blade angle

$\lambda \quad$ Flow cone angle

$\Lambda \quad$ Blade cone angle

$\Phi \quad$ Blade camber angle

$\eta_{\mathrm{ts}} \quad$ Total-to-static efficiency

CFD Computational fluid dynamics

CFV Cavity flow vortex

LE Leading edge

MFP Mass flow parameter

MFT Mixed flow turbine

PR Pressure ratio

PS Pressure side

RFT Radial flow turbine

RMS Root-mean-square

QUB Queen's University Belfast

SS Suction side

SST Shear stress transport

TE Trailing edge

TLV Tip leakage vortex

\section{ACKNOWLEDGMENTS}

The authors would like to thank IHI Charging Systems International $\mathrm{GmbH}$ for their support and technical assistance during this study. The authors would also like to extend thanks to ANSYS Inc. for the use of their CFD software and their technical support in this research.

\section{REFERENCES}

[1] Japikse, D., and Baines, N.C., 1994, "Introduction to Turbomachinery," Concepts/NREC, White River Junction, VT.

[2] Spence, S. W. T., and Artt, D. W., 1998, "An Experimental Assessment of Incidence Losses in a Radial Inflow Turbine Rotor," IMechE Journal of Power and Energy, 212(1) pp. 43-53

[3] Walkingshaw, J., Spence, S., Ehrhard, J., 2011, "An investigation into improving off-design performance in a turbocharger turbine utilizing non-radial blading," ASME Paper No. GT2011-45717.

[4] Watson, N., and Janota, M.S., 1982, "Turbocharging the internal combustion engine," The MacMillan Press Ltd.

[5] Minegishi, H., Matsushita, H., Sakakida, M., 1995, "Development of a small mixed-flow turbine for automotive turbochargers," ASME Paper No. 95-GT-053.

[6] Leonard, T., Spence, S., Early, J., 2013, "A numerical study of automotive turbocharger mixed flow turbine inlet geometry for off design performance," IOP Conference Series: Materials Science and Engineering.

[7] Leonard, T., Spence, S., Early, J., 2014, "A numerical study of inlet geometry for a low inertia mixed flow turbocharger turbine," ASME Paper No. GT2014-25850.

[8] Whitfield, A., and Baines, N.C., 1990, "Design of radial turbomachines," John Wiley and Sons Inc., New York, NY (USA).

[9] Karamanis, N., Martinez-Botas, R. F., and Su, C. C., 2001, "Mixed Flow Turbines: Inlet and Exit Flow Under Steady and Pulsating Conditions," ASME J. Turbomach., 123(2) pp. 359-371.

[10] Palfreyman, D., and Martinez-Botas, R. F., 2002, "Numerical study of the internal flow field characteristics in mixed flow turbines," ASME Paper No. GT200230372.

[11] Rajoo, S. and Martinez-Botas, R., 2008. "Variable geometry mixed flow turbine for turbochargers: an experimental study". International Journal of Fluid Machinery and Systems, 1(1), pp.155-168.

[12] Morrison, R., Spence, S., Kim, S., Filsinger, D. and Leonard, T., 2016, "Investigation of the effects of flow conditions at rotor inlet on mixed flow turbine performance for automotive applications," NLETT Turbocharging Seminar, Tianjin.

[13] Lee, S. P., Barrans, S. M., Jupp, M. L., 2018, "Investigation Into the Impact of Span-Wise Flow Distribution on the Performance of a Mixed Flow Turbine," ASME Paper No. GT2018-76992.

[14] Roclawski, H., Böhle, M., and Gugau, M., 2012, "Multidisciplinary design optimization of a mixed flow turbine wheel," ASME Paper No. GT2012-68233.

[15] Leonard, T., Spence, S., Filsinger, D., 2018, "A Numerical and Experimental Investigation of the Impact of Mixed Flow Turbine Inlet Cone Angle and Inlet Blade Angle," ASME Paper No. GT2018-75096.

[16] Walkingshaw, J., Spence, S., Ehrhard, J., 2010, "A numerical study of the flow fields in a highly off-design variable geometry turbine," ASME Paper No. GT201022669.

[17] Simpson, A., Spence, S., and Watterson, J., 2013, "Numerical and Experimental Study of the Performance Effects of Varying Vaneless Space and Vane Solidity in Radial Turbine Stators," ASME J Turbomach., 135(3) pp. 031001.

[18] Simpson, A., Spence, S. W., Artt, D. W., 2006, "Experimental and numerical investigation of varying stator design parameters for a radial turbine," ASME Paper No. GT2006-90152. 